\title{
ANTIBIOTIC PRESCRIPTION PRACTICES FOR CHILDREN ADMITTED WITH RESPIRATORY ILLNESSES IN ANSONGO, NORTHEN MALI : A RETROSPECTIVE STUDY
}

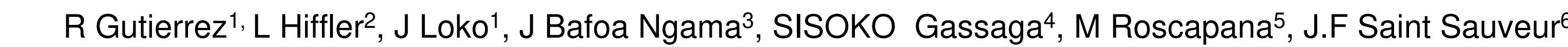

${ }^{1} \mathrm{MSF}$ Spain Epidemiology referent - Medical Department - Barcelona ${ }^{2}$ Paediatric advisor-MSF Spain Dakar unit- Senegal ${ }_{1}^{3}$ Medical coordinator MSF Spain - Mali; ${ }^{4}$ Medical District Chief - Ansongo - Mali; ${ }^{5}$ Medical operational coordinator to Mali- Cell 2 - Barcelona- MSF Spain, ${ }^{6}$ Medical Director, MSF Spain

\section{BACKGROUND}

Background: Sub-Saharan Africa has one of the highest burdens of deaths caused by infectious diseases. Indeed it is one of the 7 countries with the worst under 5 mortality rate in the world. Inappropriate use of antibiotics (ABTs) has been identified as one of the multiple causes of antimicrobial resistance. Since 2012 MSF is working with the ministry of Health in the reference health centre (CSREF) of Ansongo in an on-going conflict area of Northern Mali.

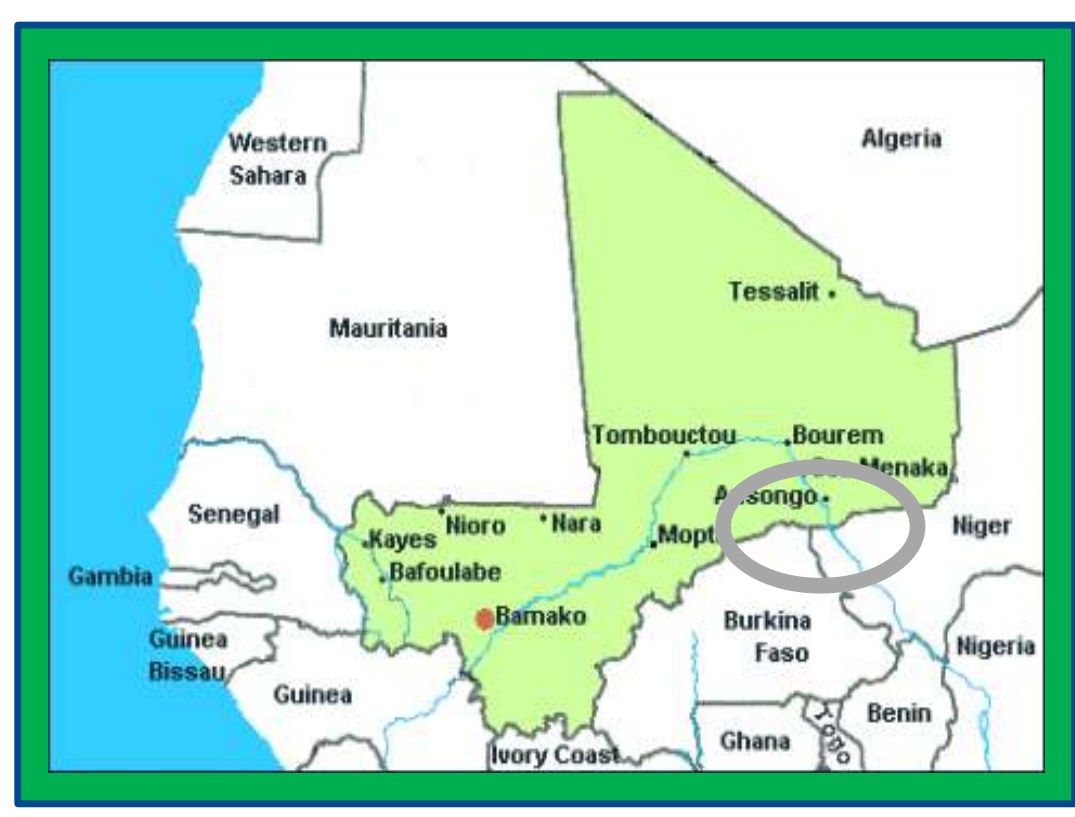

\section{METHOD:}

Retrospective cohort of patients from the paediatric Inpatient department (IPD) of the CSREF in Ansongo.

Inclusion Criteria: Patients ages 0 to 180 months (15 years) admitted as in-patients in Ansongo's CSREF between January 1st 2015 and December $31^{\text {st }}$ 2015. Medical records must be complete with information regarding general information, signs and symptoms, clinical examination, suspected diagnostics and therapeutics.

Exclusion Criteria: Ages beyond 15 years; patient not requiring / accepting treatment as an IPD.

Missing information from the patient files. (incomplete files)

Data Collection:

Information was collected by a data encoder. The patients were not identified by name, instead a unique code was used for identification. The information collected consists of:

Patient Code, Age, Gender, Origin, Weight, Date of admission and discharge

Patient Signs and Symptoms: Symptoms (up to 5), respiratory frequency, temperature (on admission and on day 3), any signs of the physical examination, result from Malaria Rapid Test and from Hemocue $(\mathrm{Hb})$

Diagnostic: Entry diagnostic and exit diagnostic (only one for each).

Therapeutic: Medication prescribed (name, dose, route of administration and day it started). Any medication taken by the patient was included (no limit).

Secondary analysis: patients with any diagnosis of respiratory illnesses were analysed here.

\section{RESULTS:}

398 patient files were reviewed. Median age was 24 months. Respiratory conditions represented $35,2 \%$ of total admissions. The respiratory conditions were further stratified into 2 groups (table 1).

- Group 1: Pneumonia, Respiratory distress, Tuberculosis, Tonsillitis, Otitis Media, representing $18,6 \%$ of total respiratory admissions.

- Group 2 : Asthma, Bronchiolitis, Bronchitis, "Flu", "Upper Respiratory Tract Infections" : 81,4\% of total.

All received at least $1 \mathrm{ABT}$. $53.8 \%(\mathrm{G} 1)$ and $54,4 \%(\mathrm{G} 2)$ received 2 ABTs or more. $15.39 \%(G 1)$ and $13.15 \%$ (G2) received 3 ABTs or more. In both groups, most frequent $A B T$ used were ampicillin and gentamicin $(31.8 \% ; 34 \%$ and $27.3 \% ; 26.3 \%$ respectively) followed by C3G ceftriaxone $(18.18 \% ; 22.2 \%)$

\begin{tabular}{|c|c|c|c|c|}
\hline & N=140 & $\begin{array}{c}\geq 1 \\
\text { Antibiotic }\end{array}$ & $\begin{array}{c}\geq 2 \\
\text { Antibiotics }\end{array}$ & $\begin{array}{c}\text { No } \\
\text { Antibiotic }\end{array}$ \\
\hline Group 1 & $18.6 \%$ & $100 \%$ & $53.8 \%$ & $0 \%$ \\
\hline Group 2 & $81.4 \%$ & $100 \%$ & $54.4 \%$ & $0 \%$ \\
\hline
\end{tabular}

Table 1: Antibiotics received per sub-groups of respiratory illnesses

\section{DISCUSSION}

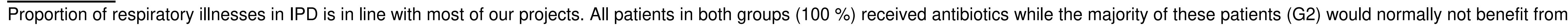

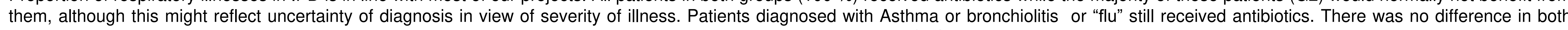

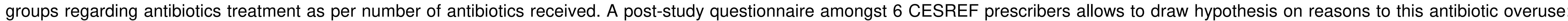

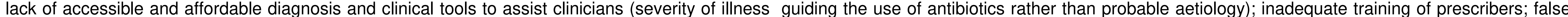
assumption that antibiotics will prevent superinfection or reduce hospital length of stay.

\section{CONCLUSION:}

This study is a description of antibiotics prescription practices in 2015 in the paediatric IPD of CESREF Ansongo, Northern Mali.

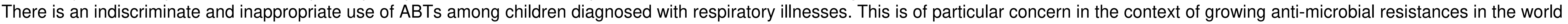
and particularly sub-Saharan Africa. Trainings, staff capacity building, point of care diagnostic tools, innovative interventions need to be developed.

Context adapted, antibiotic rational use programmes and promotion of illness-specific treatment need to be put in place urgently. 